\title{
Potential Prebiotic Relevance of Glycine Single Crystals Enclosing Fluid Inclusions: An Experimental and Computer Simulation with Static Magnetic Fields
}

\author{
E. Angeles-Camacho1,2, J. Cruz-Castañeda1,3, A. Meléndez 1,3, M. Colín-García ${ }^{4}$, \\ K. Cervantes de la Cruz',5, S. Ramos-Bernal1, A. Negrón-Mendoza1, G. Garza-Ramos', \\ P. Rodríguez-Zamora ${ }^{7}$, C. Camargo-Raya ${ }^{1}$, A. Heredia ${ }^{1 *}$ \\ ${ }^{1}$ Instituto de Ciencias Nucleares, Universidad Nacional Autónoma de México, Mexico City, México \\ ${ }^{2}$ Facultad de Química, Universidad Nacional Autónoma de México, Ciudad Universitaria, Mexico City, México \\ ${ }^{3}$ Programa de Maestría y Doctorado en Ciencias Químicas, UNAM. Cd. Universitaria, Mexico City, México \\ ${ }^{4}$ Instituto de Geología, Universidad Nacional Autónoma de México, Mexico City, México \\ ${ }^{5}$ Departamento de Física, Coordinación de Ciencias de la Tierra, Facultad de Ciencias, Universidad Nacional Autónoma de \\ México, Mexico City, México \\ ${ }^{6}$ Departamento de Bioquímica, Facultad de Medicina, Universidad Nacional Autónoma de México, \\ Mexico City, México \\ ${ }^{7}$ Instituto de Física-UNAM, Circuito de la Investigación Científica, Ciudad Universitaria, Mexico City, México \\ Email:^aheredia@nucleares.unam.mx
}

How to cite this paper: Angeles-Camacho, E., Cruz-Castañeda, J., Meléndez, A., ColínGarcía, M., de la Cruz, K.C., Ramos-Bernal, S., Negrón-Mendoza, A., Garza-Ramos, G., Rodríguez-Zamora, P., Camargo-Raya, C. and Heredia, A. (2020) Potential Prebiotic Relevance of Glycine Single Crystals Enclosing Fluid Inclusions: An Experimental and Computer Simulation with Static Magnetic Fields. Advances in Biological Chemistry, 10, 140-156.

https://doi.org/10.4236/abc.2020.105011

Received: September 8, 2020

Accepted: October 27, 2020

Published: October 30, 2020

\begin{abstract}
Glycine crystallizes into three different polymorphs called $\alpha, \beta$ and $\gamma$ under standard physicochemical conditions. They have different features depending on their structural variations. The possible interaction of glycine with magnetic minerals in meteorites and comets or in the ancient Earth, paves the way to study the self-assembly and molecular behavior under irradiation and magnetic conditions. The magnetic field might induce the formation of a specific polymorph of glycine. To gain insight on the consequences of gamma irradiation with a gradient of static magnetic fields $(0.06 \mathrm{~T}, 0.3 \mathrm{~T}, 0.42 \mathrm{~T}$ and $0.6 \mathrm{~T}$ ) on the self-assembly of single macroscopic glycine crystals, we gamma irradiated the powdered amino acid and then assembled single crystals from water solutions. The preliminary results showed a stable formation of fluid inclusions in the single crystals and no straightforward effect on the self-assembly process after glycine gamma irradiation and interaction with static magnetic fields. The $\alpha$ glycine polymorph single crystals formed at $55^{\circ}$ from the magnetic longitudinal axis and seemed to be enhanced by gamma radiation. The $\gamma$-glycine single crystals presented L and D circular dichroism signals,
\end{abstract}


Copyright $\odot 2020$ by author(s) and Scientific Research Publishing Inc. This work is licensed under the Creative Commons Attribution International License (CC BY 4.0).

http://creativecommons.org/licenses/by/4.0/ whereas the irradiated samples presented no circular dichroism bands. Computer simulations suggest different catalytic properties from $\alpha$ and $\gamma$ glycine crystals.

\section{Keywords}

Glycine Polymorphs, Fluid Inclusions, Gamma Irradiation, Chemical Evolution, FT-IR, Circular Dichroism, Chiral Crystals

\section{Introduction}

How life originated is not known but the assumptions exist from different points of view [1]. From the scientific point of view, some molecules such as amino acids are essentials for life, since they are the molecules that make up proteins. Therefore, they are indispensable units in studies related to chemical evolution [2]. How the small molecules such as glycine eventually might have oligomerized in a more complex system on early Earth? Prebiotic chemistry [3] [4] [5] [6] and chemical evolution [7] are especially concerned with these topics on amino acids, cyclic peptides [8] [9] and alkanes [10]-[17]. The study of the consequences of the gamma irradiation of amino acids in solid state and their further solvation in water for self-assembly is not a common research making this study a necessary effort to understand the chemical evolution of glycine under conditions similar to those in ancient Earth and cometary conditions [18] [19] [20]. Glycine is the simplest biological amino acid $\left({ }^{+} \mathrm{NH}_{3} \mathrm{CH}_{2} \mathrm{CO}_{2}^{-}\right)$with no molecular chirality, although after its crystallization, it presents circular dichroism signal [21]. Glycine was the first amino acid found in comets and meteorites [22] [23] [24]. Glycine is the most studied amino acid, although commonly the physicochemical properties of crystals are not considered [25] [26]. Possible relevant properties of glycine are its catalytic features [27] [28] [29] [30] [31] and its magnetic susceptibility [32]. Some authors assembly glycine single crystals oriented at ca. $45^{\circ}$ from the axis parallel to the magnetic field [32]. Magnetic susceptibility is found in macromolecules such as lysozyme too [33]. In the self-assemblies of glycine, it is possible that magnetic fields induce the formation of a polymorph [28] among its $\alpha, \beta$ and $\gamma$ crystal structures [34] [35] [36] [37]. The $\alpha$-glycine single crystals are the easiest to obtain [25] possessing magnetic susceptibility. For these physicochemical properties, the description of the stability of the fluid inclusions in glycine is relevant for prebiotic chemistry [24] [28]-[43]. Furthermore, local magnetic fields are relevant in interstellar space because they might shield amino acids and other organic compounds from the solar wind and cosmic radiation [20] [41] [44] that produces free radicals [45] experimentally detectable with the electron paramagnetic resonance (EPR) [46]. EPR signal gives different structural properties in systems with free radicals interacting with the magnetic field such as the g-tensor value (strength against the movement of the electron in the magnetic field) or the hyperfine coupling (interaction of the nucleus of the atom 
with the paramagnetic electron). In this work, we studied the structural differences in crystallization or the so-called self-assembly process of glycine in water solutions. In our experimental procedure, glycine is gamma irradiated (a similar dose to that in a comet [44] [47] and further put to interact with static magnetic fields for its self-assembly. We emphasize the formation of fluid inclusions in chiral single crystals and performed computer simulations to do and insight at the molecule-scale on the possible catalytic performance of chiral glycine crystals. Computer simulations might give valuable information about the oligomerization process under the hydration-dehydration conditions.

\section{Experimental}

\subsection{Irradiation and Sample Preparation}

Glycine powder (Sigma-Aldrich, 98.5\% purity, USA) was exposed to ionizing radiation under a gamma beam source (Gammabeam 651-PT facility at the Instituto de Ciencias Nucleares, UNAM) at a dose of $357.84 \mathrm{kGy}$. After gamma irradiation and self-assembly of glycine from water solutions (MiliQ Plus, Millipore 0.055 $\mu \mathrm{S} \cdot \mathrm{cm}^{-1}, 5 \mathrm{~mL}$ casted in Petri dishes for slow evaporation) [48], the presence of the different glycine polymorphs has been confirmed by $\mathrm{X}$ ray diffraction analysis [28]. Petri dishes were put in contact with 1, 5, 7 and 10 magnets (Figure 1) (0.06 tesla ( $\mathrm{T}$ ) each magnet, (Daiso Industries, Hiroshima, Japan) to perform crystallization experiments to do an insight in the behavior of the glycine solutions interacting to magnetic materials, simulating either the surface of the Ancient Earth or other celestial objects.

The angles between the longitudinal axis of the single glycine crystals and the magnetic longitudinal axis, were measured by using GeoGebra ${ }^{\circledR}$ software (Linz, Austria) and their values obtained as the number of magnets increased (Figure 2(a) and Figure 2(b)).

\subsection{Electron Paramagnetic Resonance (EPR)}

The presence of the free radical was confirmed in the irradiated glycine powder by electronic paramagnetic resonance (Jeol instrument JES-TE300 EPR spectrometer, operating in the $\mathrm{X}$-Band, with a modulation frequency of $100 \mathrm{kHz}$ in a cylindrical cavity in the $\mathrm{TE}_{011}$ mode). The crystals of glycine were placed in quartz tubes (Wilmad Glass Company, Buena, NJ, USA). For this experimental procedure, the external calibration of the magnetic field was performed in a JEOL ES-FC5 precision gaussmeter. The EPR spectra were obtained by using the ESIPRITS/TE program.

\subsection{High Performance Liquid Chromatography-Electrospray Ionization in Negative Mode-Mass Spectrometry Analysis (HPLC-ESI--MS)}

The liquid chromatography analysis was performed on an HPLC system (515pump from Waters Corp.), coupled with a Single Quadrupole Mass Detection 
system (SQ-2 manufactured by Waters Corp.), and an electrospray ionization instrument in negative mode (ESI ${ }^{-}$). The working conditions were adjusted for capillary of $2.58 \mathrm{kV}$, cone of $51 \mathrm{~V}$, at a temperature of $350^{\circ} \mathrm{C}$, and a desolvation gas flow of $650 \mathrm{~L} / \mathrm{h}$, using a Symmetry C18 column $(4.6 \times 75 \mathrm{~mm}, 3.5 \mu \mathrm{m}$ spherical particle size, by Waters Corp.) under an isocratic elution of a mobile phase ( $50 \%$ methanol and $50 \%$ water at $\mathrm{pH}=7$ ), and at flow of $0.4 \mathrm{~mL} / \mathrm{min}$. A sample volume $(20 \mu \mathrm{L})$ was injected using a loop. For the preparation of the samples for MS, single crystals (ca. $7.5 \mathrm{mg}$ ) were dissolved in tridistilled water and then injected into the instrument.

\subsection{Attenuated Total Reflectance Fourier Transform Infrared Spectroscopy (ATR-FTIR)}

Glycine polymorphs were characterized by their vibrational FTIR spectra [49]. These spectra were obtained in an ATR-FTIR instrument with a universal ATR accessory (absorbance mode from 4000 to $650 \mathrm{~cm}^{-1}$ and a resolution of $4 \mathrm{~cm}^{-1}$ over 4 scans per sample. A 100 FTIR Spectrometer, Perkin Elmer, Massachusetts, USA was used). Glycine polymorphs have structural differences, which makes it feasible to characterize them through their infrared spectra [37]. The crystals were taken from the Petri dishes and afterwards, the spectra were obtained, and the second derivative method applied [50] [51] [52]. The second derivative of the FTIR absorbance is useful to increase the resolution of the bands as follows:

According to the Lambert-Beer Law absorbance can be represented as:

$$
A=\varepsilon c l
$$

where $A=$ absorbance of the sample, $\varepsilon=$ molar absorption coefficient, $c=$ analyte concentration and $I=$ length of solution the light passes through. If absorbance is a function that depends on the wavelength and a second derivative is applied to it:

$$
\begin{gathered}
A=f(\lambda) \\
\frac{\mathrm{d}^{2} A}{\mathrm{~d} \lambda^{2}}=f^{\prime \prime}(\lambda)
\end{gathered}
$$

Here, it is observed that quantitative information can also be obtained from the spectra of the second derivative, since $l$ and $c$, as constant terms, are not affected by the derivative.

\subsection{Polarized Light Microscopy}

Polarized light microscopy was used to gain insight into the different glycine polymorphs and the presence of fluid inclusions (BA310Pol Motic Microscope, coupled to a Motic10cmos digital camera, British Columbia, Canada). $\alpha$ or $\gamma$ polymorphs are different under polarized microscopy [53] [54]. The polarized light microscope was used to analyze samples from the crystalline material with less than $3 \mathrm{~mm}$ [55]. Using the polarized-light microscope, monoclinic crystals can 
be distinguished from trigonal ones by their extinction angle. This method is described in traditional thin section microscope studies [56]. The way to find the extinction angle is by reading the angle position from the Vernier on the microscope stage: 1) morphological element (faces of crystal parallel to the $c$-axes) is collocated parallel to N-S line of the cross hairs of microscope, then, 2) stage is rotated until the extinction position and 3) read the angle between first and last position. Hexagonal-trigonal crystals show straight and/or symmetrical extinction while monoclinic crystals have inclined extinction.

\subsection{Circular Dichroism}

Circular dichroism (CD) measurements of glycine single crystals were performed on a Jasco J-715 CD spectrometer (Jasco International, Tokyo, Japan), mounted inside quartz cuvettes (Wildmad glass, Buena, NJ, USA) with a path length of 5.0 $\mathrm{mm}$ at $25^{\circ} \mathrm{C}$. Data were averaged over three scans and collected in a range of 200 - $600 \mathrm{~nm}$ with a resolution of $1 \mathrm{~nm}$, bandwidth of $2 \mathrm{~nm}$, and sensitivity of 50 mdeg at $50 \mathrm{~nm} / \mathrm{min}$. The single crystals of glycine were mounted at the center of the cell, thus ensuring the positioning in the laser pathway of the spectrometer. Data of at least three single crystals of each sample (non-irradiated glycine crystals, irradiated glycine crystals and non-radiated and irradiated glycine crystals affected by an external magnetic field) were acquired.

\subsection{Computational Models}

Computational models were performed in HyperChem8.0.1 ${ }^{\circledR}$ software (Hypercube, Florida, USA). To better insight in the potential route of molecule formation of dimers of glycine and chiral dimers of alanine onto chiral glycine helices, we preformed different computer simulations. Computer simulations were implemented to have data about the feasible catalytic performance of glycine single crystals. The different chiral crystalline structures of glycine were edited in the HyperChem workspace. Chiral structures were performed by applying the mirror symmetry to molecules (Select $\rightarrow$ Name Selection $\rightarrow$ Plane Edit $\rightarrow$ Reflect). The crystalline structures were not optimized in order to avoid losing the crystallographic parameters. The simulations of the possible catalytic chemical performance of the glycine chiral crystals [21] were carried out through a dimerization process. The simulated reaction consists of the formation of dimers of Gly and Ala, onto D and L chiral glycine templates. Other already published approaches have no chiral templates [29]. First, the MM+ method was used to geometrically optimize the molecules (MM+ force field, the Polak-Ribiere conjugate gradient algorithm, and a root mean square gradient (RMS) of $0.001 \mathrm{kcal} \cdot \AA^{-1} \cdot \mathrm{mol}^{-1}$ ) and afterwards, the $P M 3$ semi-empirical method was used [57] to geometrically optimize the molecules and obtain the thermodynamic parameters in the dimerization process (Polak-Ribiere conjugate gradient algorithm, and a root mean square gradient (RMS) of $\left.0.001 \mathrm{kcal} \cdot \AA^{-1} \cdot \mathrm{mol}^{-1}\right)$. 


\section{Results and Discussion}

Gamma irradiation generates free radicals in the powder of glycine (Figure 1) before crystallization occurs [58] [59] [60]. There are different EPR studies that analyze the free radicals, but fundamentally, we rely on a direct comparison [59] [61]. A common free radical in amino acids is identified as the ${ }^{+} \mathrm{NH}_{3} \dot{\mathrm{C}} \mathrm{HCO}_{2}^{-}$ chemical group and has about a $2.004 \mathrm{~g}$ value from the EPR analysis (Figure 1). After their crystallization, irradiated glycine crystals presented no EPR signal (results not shown).

Glycine single crystals, in their self-assembly process, coordinate in space with the longitudinal axis of the magnets of (Figure 2), which also confirms other experimental results [32] [63].

Figure 2(c) reveals that at small magnetic fields, there is a value of $c a .60^{\circ}$ for the controls and the irradiated samples. The values corresponding to 1, 5, 7 magnets in general are very similar in the angles of crystal orientation up to a value of $\mathrm{ca} .40^{\circ}$ at 10 magnets for the controls and the irradiated samples. The Figure 2(c) shows the standard deviation or divergence in angles from the single crystals relative to the longitudinal axis of the magnets. It shows less degree of organization in the crystal orientation from irradiated glycine after the selfassembly of single crystals. This behavior agrees with the fact that magnetic fields might crystalize more $\gamma$ glycine with no magnetic susceptibility [28]. Another relevant phenomenon for prebiotic chemistry, through the assembly of single crystals, is the oligomerization of the glycine amino acid in the hydration-dehydration process (Figure 3) [28] [64]. For instance, in the mass spectrometry (MS) results (Figure $3(\mathrm{~b})$ and Figure $3(\mathrm{c})$ ), the mass signals of glycine $(74 \mathrm{~g} / \mathrm{mol})$ and the possible dimers with peptide bond $(c a .131 \mathrm{~g} / \mathrm{mol})$, the dimer with no peptide bond ( $c a .148 \mathrm{~g} / \mathrm{mol}$, with low intensity, not shown) and trimers are seen (ca. 189 and $220 \mathrm{~g} / \mathrm{mol}$, with low intensity, not shown).

In other studies [63] the authors found angles of $c a .55^{\circ}$ which are like the results

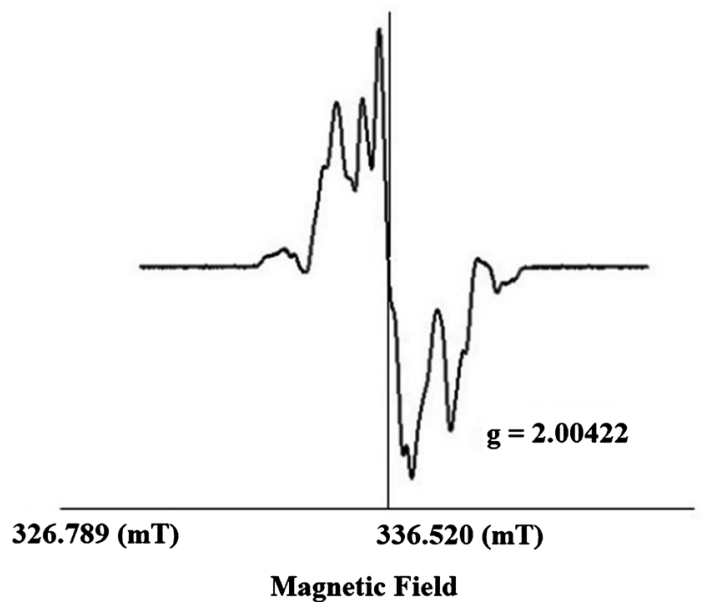

Figure 1. EPR spectrum of irradiated glycine (357.84 kGy.). The $g$ value (2.004) suggests shielding on the spin of the electrons that tighten them against the movement produced by the magnetic field [62]. 


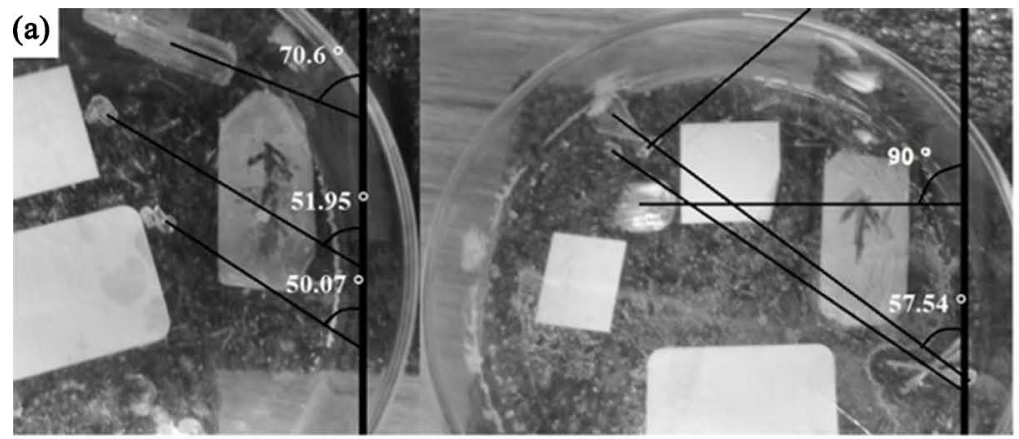

(c)
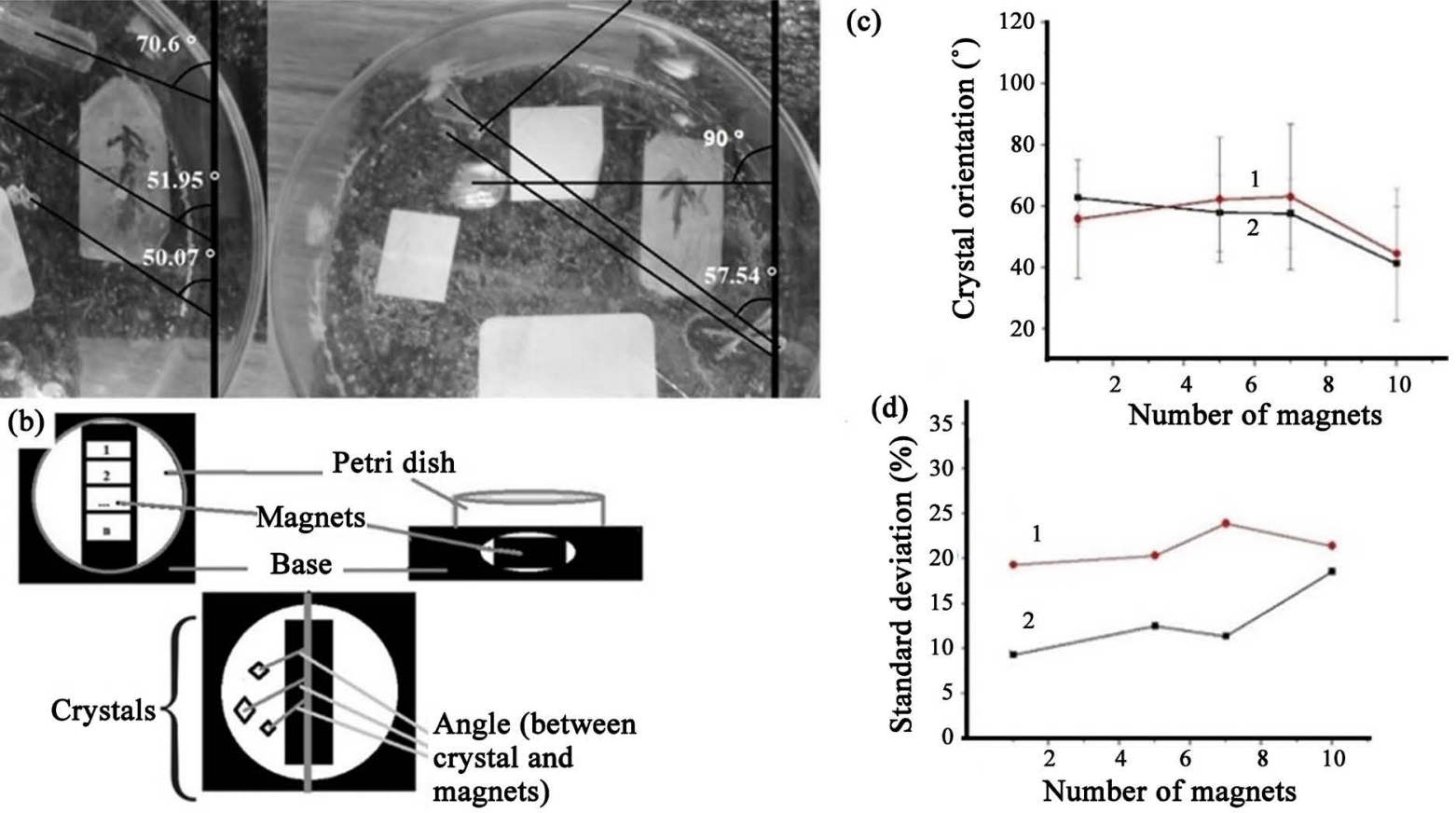

Figure 2. (a) Set up to grow the single crystals of glycine in Petri dishes and the procedure to measure the angles between the single crystals and the magnetic fields. To guide the eye, the upright line represents the direction of the magnetic field. (b) Scheme showing the set up to grow glycine single crystals. (c) Shows the orientation of the crystals relative to the longitudinal axis of the magnetic fields and (d) shows the crystal orientation diversity; 1) Irradiated glycine and 2) control sample.

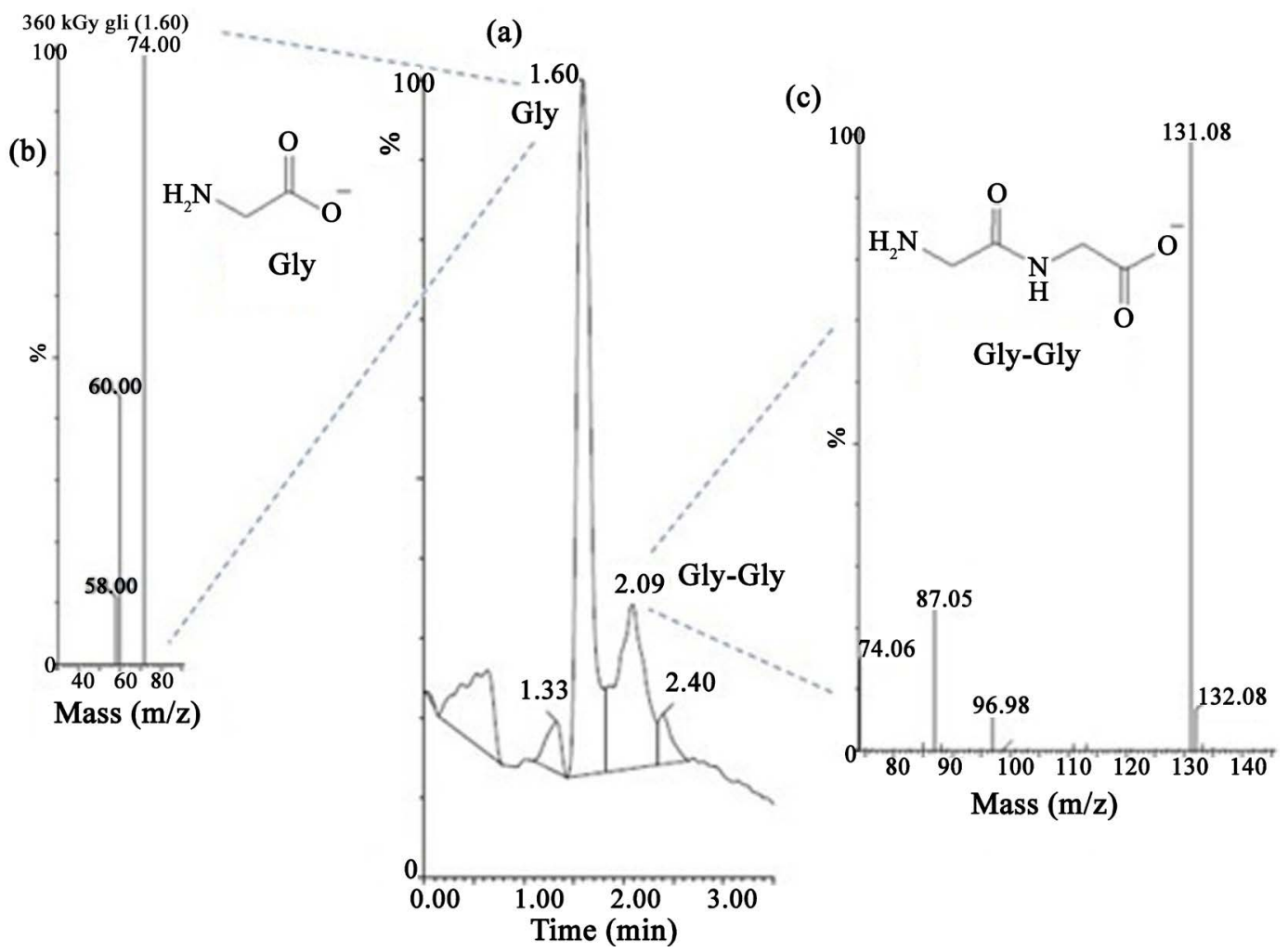

Figure 3. (a) Shows the High-Performance Liquid Chromatography (HPLC) and the mass spectra of the control sample (b) and (c) of the irradiated samples. A possible formation of dimers and trimers is seen with different masses at $131 \mathrm{~g} / \mathrm{mol}$ (other masses are observed at 149, 189 and $222 \mathrm{~g} / \mathrm{mol}$, not shown). 
in this study (Figure 3(a)).

These results might be explained because the gamma radiation generated different radical species, thus modifying the assembly of the crystalline structure.

\subsection{ATR-Infrared Spectroscopy}

The $a$ and $\gamma$ polymorphs crystallize in $\mathrm{P} 2 / \mathrm{n}$ (monoclinic) and $\mathrm{P} 3 / 2$ (trigonal) space groups respectively [36] and are identified by their infrared spectra (Figure 4(a)) [37]. Glycine polymorphs have a common band at $890 \mathrm{~cm}^{-1}$ however, characteristic bands (or "fingerprint bands") are found at $910 \mathrm{~cm}^{-1}$ for the $\alpha$-glycine and at $930 \mathrm{~cm}^{-1}$ for $\gamma$-glycine (Figure 4(b), Figure 4(c)) [37]. These bands originate in the molecular vibrations (stretching) from the $v$ CC group at ca. 890 $\mathrm{cm}^{-1}$ and (rocking) of $\rho \mathrm{CH}_{2}$ at $910 / 930 \mathrm{~cm}^{-1}$ [65]. It may be useful to visualize through ATR-FTIR second derivatives (Figure 4(b)). Once the bands are identified, it is possible to analyze their intensities through the interaction with the magnets (4D). In these results, the increase in the relative values of the $930 \mathrm{~cm}^{-1}$ band display a possible self-assembly towards the formation of the glycine $\gamma$ polymorph under the effect of the magnetic fields.
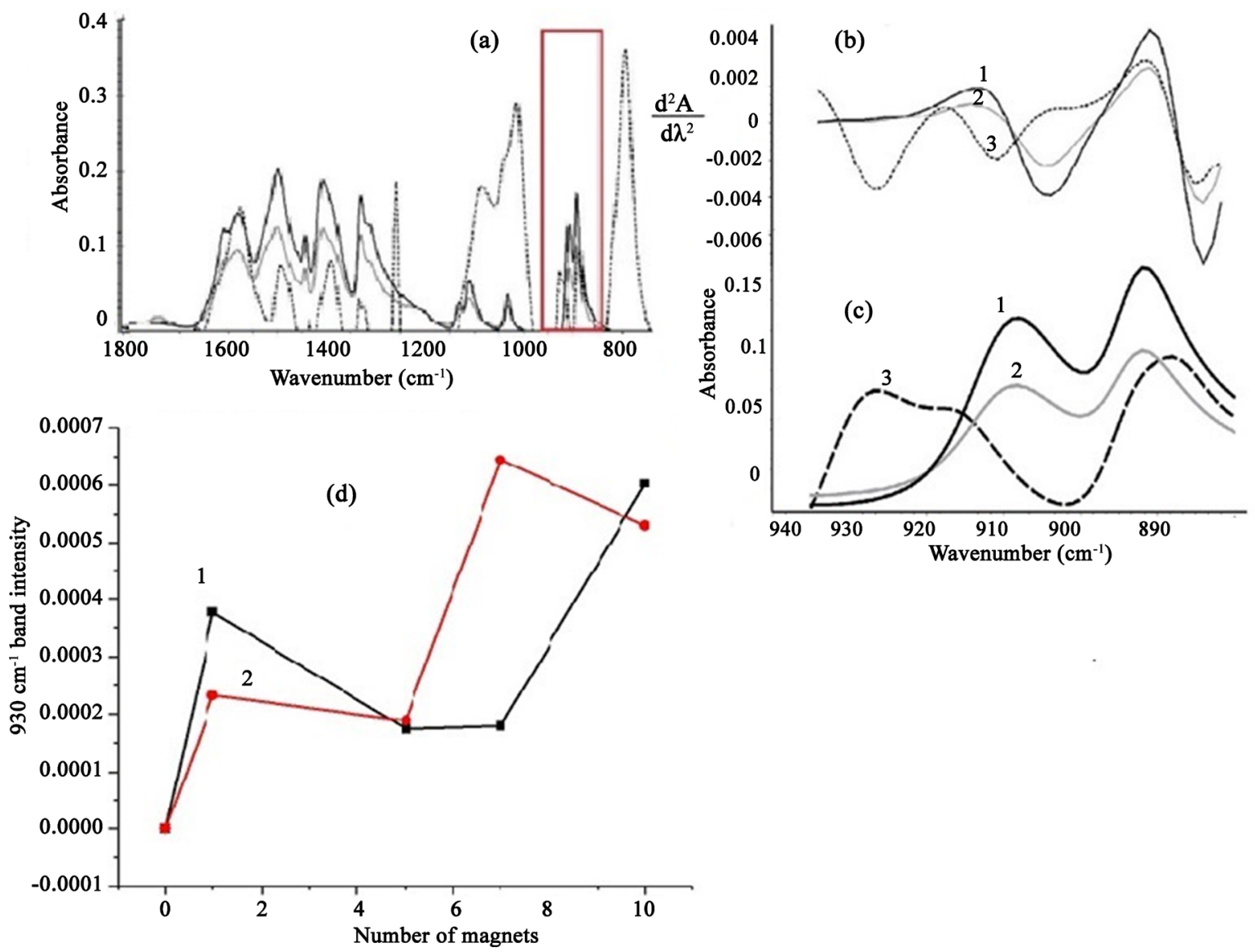

Figure 4. (a) IR spectra of control (black line), irradiated (gray line) and $\gamma$ polymorph (dotted line) of the glycine samples. The fingerprint region (910 and $891 \mathrm{~cm}^{-1}$ ) in (b) and (c) is used to identify the different glycine polymorphs; 1 and 2 correspond to the $\alpha$-polymorph and 3 to the $\gamma$-polymorph. (d) Shows the assembly of the $\gamma$ glycine polymorph through the $930 \mathrm{~cm}^{-1}$ band interacting with the magnets. 
The ATR-FTIR analysis, is focused on the changes that might have occurred in the fingerprint bands, considering that the vibrational frequencies are affected by the intermolecular interactions. A shift in a band possibly corresponding to the $\rho \mathrm{CH}_{2}$ group in the $\alpha$-glycine crystal lattice was observed (Figures 4 (b)-(d)). In contrast, the crystal lattice in the $\gamma$ polymorph (Figures 4(b)-(d)) might have wider vibrations in the alpha carbon. Indeed, the $\gamma$ polymorph presents more volume per molecule in the unit cell, thus confirming this assumption [36].

\subsection{Glycine Single Crystals Present Fluid Inclusions and Chirality}

Some studies performed powder $\mathrm{X}$ ray diffraction to confirm the structural changes in glycine polymorphs through the gamma irradiation process [28] although the individual characterization of single crystals is imperative. The characterization with the polarized light microscopy (PLM) of individual single crystals paves the way to describe the fine inner structure of these organic solids (Figure 5). $\alpha$ or $\gamma$ polymorphs are different under the polarized light microscopy [53] [54]. $\alpha$ glycine is a monoclinic polymorph and its crystal shows prismatic morphology elongated in its $c$ crystal axis (Figure 5) [66] contrasting with the trigonal polymorph of the $\gamma$ glycine showing a rhombohedral structure [66] [67].

After the polarized light microscopy (PLM) and circular dichroism analysis, it was possible to determine that a mixture of polymorphs was present in the Petri dishes. In monoclinic prismatic crystals, the light is extinguished at angles other than $90^{\circ}$ and those crystals are identified as the alpha polymorph. Microscope light extinction at $90^{\circ}$ corresponds to the $\gamma$ glycine polymorph.

The crystals of glycine commonly presented fluid inclusions (Figure 5, Figure 6). These spaces of liquid or gas trapped inside the crystals, might be of relevance to preserve organic molecules for prebiotic reactions. These possible chemical reactions might occur at the fluid-crystal interface giving relevance to the molecular packing in space of glycine units. The molecular pattern of glycine molecules in single crystals, the chirality or polymorph formation, conducts the different possible catalytic properties at the molecule scale.

The characterization through circular dichroism confirmed the chiral nature of the glycine $\gamma$ polymorph single crystals (Figure 7) [21]. After the gamma irradiation

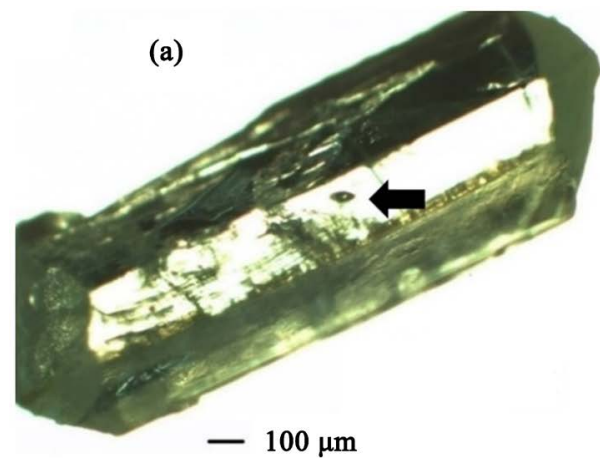

(b)

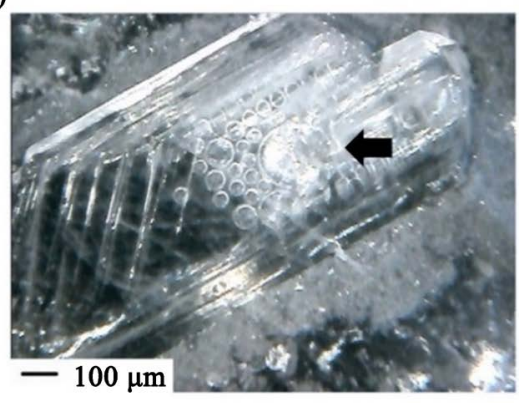

Figure 5. Glycine single crystals under the light microscope. In (a) and (b) different crystals show fluid inclusions (black arrows). 


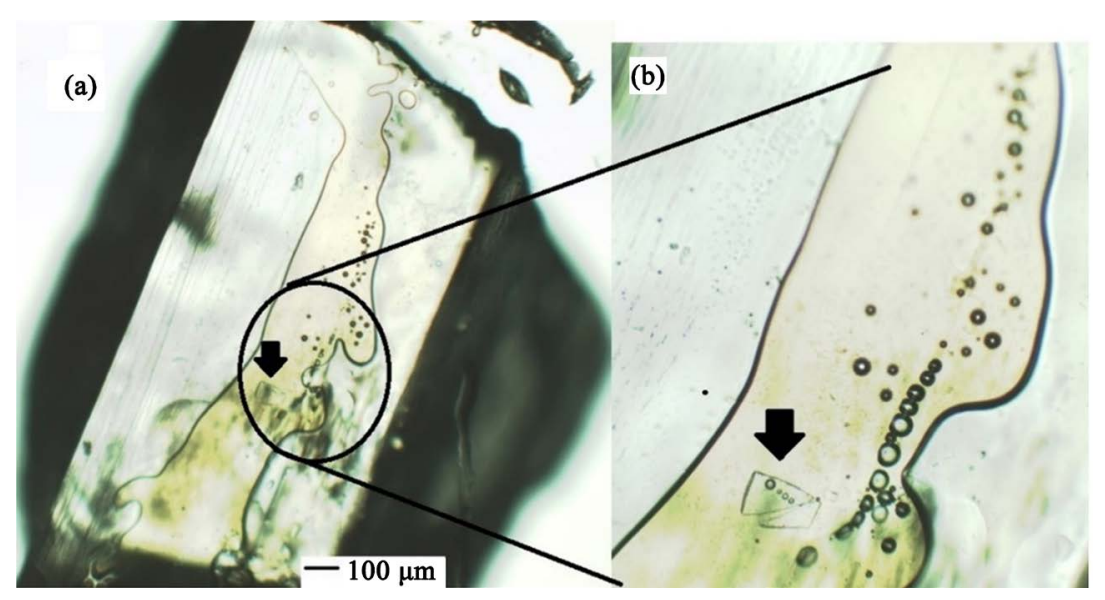

Figure 6. Single crystals of glycine, exhibit fluid inclusions at different scales.

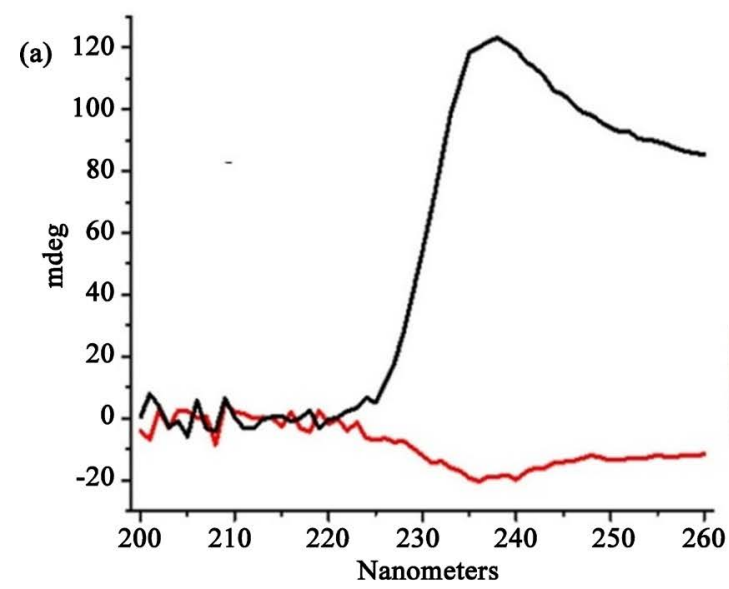

(b)

Figure 7. (a) $\gamma$ glycine single crystals with no gamma irradiation, present chiral signal under the circular dichroism analysis (both opposite signals come from two different enantiomer $\gamma$ single crystals). (b) Shows a schematic representation of the glycine molecules forming chiral helices.

of the glycine, the self-assemblies identified as $\gamma$ glycine, presented no circular dichroism signal. The breaking of the chiral symmetry has been reported in nanostructures with no clear explanation of this phenomenon at the molecule scale [68].

\subsection{Simulation of a Dimerization of Chiral Alanine onto Chiral Glycine Templates}

Oligomerization of amino acids is a common observation in molecular evolution and prebiotic chemistry experiments as formation of Alanine dimers [69] [70]. The formation of a dimer of alanine molecules from the enantiomers $\mathrm{L}$ and $\mathrm{D}$ in contact with chiral L and D helices of glycine crystal surfaces has been simulated to give an insight in their possible contrasting catalytic effects. Amino acids such as glycine, might act as organic catalysts indeed [71].

Figure 8 shows the heats of formation obtained in different computer simulations by means of the PM3 semi-empirical method. The possible catalytic role of 

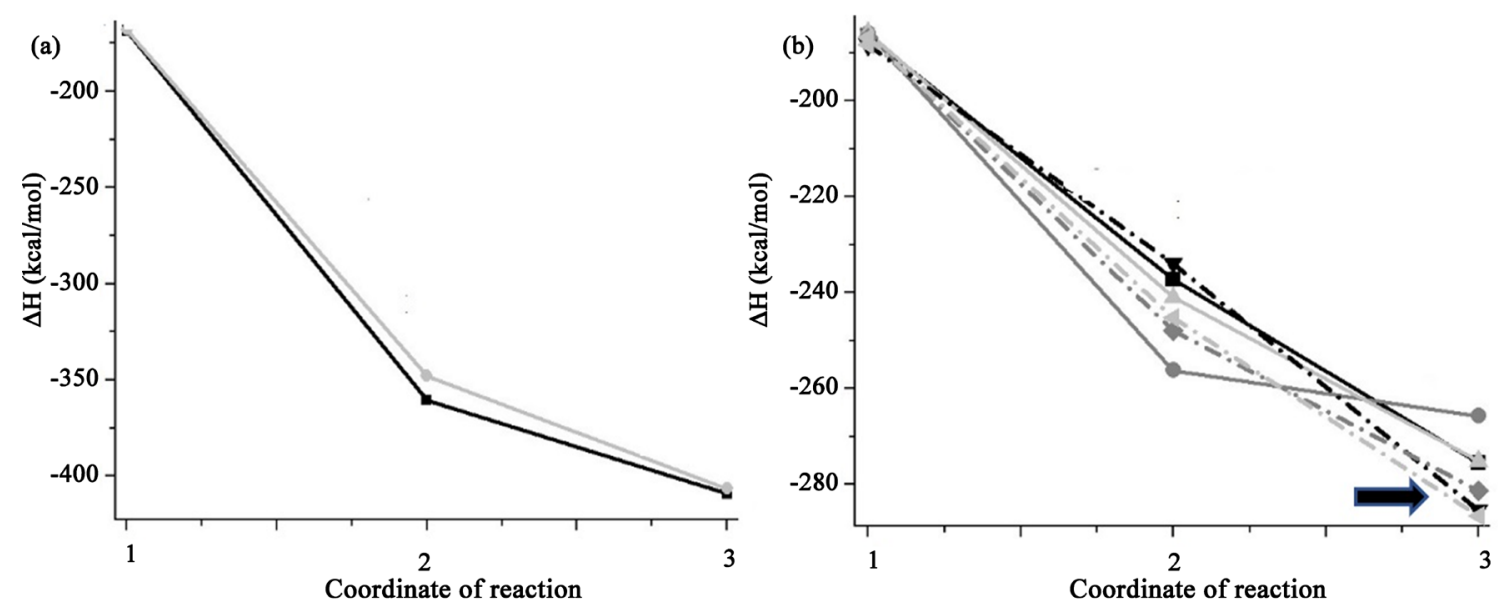

Figure 8. Computer simulations of the $\gamma$ glycine chiral helices as promoters for dimerization of amino acids. The coordinate of reaction corresponds respectively to 1 to one amino acid, 2 to two amino acids, and 3 for the formation of the dimer of amino acids. (a) In gray, the heat of formation $(\Delta \mathrm{H})$ of a single molecule of glycine interacting with the simulated glycine D-helix. In black, the interaction of a single glycine with the glycine L-helix. In (b) Continuous line are the amino acids interacting with the D-helix whereas the dashed line with the L-helix. The heat of formation $(\Delta \mathrm{H})$ of $\rightarrow$ L-Alanine, $\rightarrow$ D-Alanine, - L, D-Alanine interacting with a D-helix glycine crystal and $\boldsymbol{\nabla}$. L-Alanine, $-\leftarrow$ D-Alanine and $-\leftarrow$ L, D-Alanine interacting with a L-helix glycine crystal. A possible thermodynamic preference is seen in the L-helix (black arrow in (b)).

the $\mathrm{D}$ and $\mathrm{L}$ helices of glycine crystals were explored, resulting in different $\Delta \mathrm{H}$ values. The simulations involving glycine dimers (ca. $-400 \mathrm{kcal} / \mathrm{mol}$, Figure $8(\mathrm{a})$ ) are energetically favored contrasting with the formation of alanine dimers (ca. $-280 \mathrm{kcal} / \mathrm{mol}$, Figure $8(\mathrm{~b}))$. Nevertheless, the simulations of the dimerization process carried out with alanine by using a $\mathrm{D}$ and L-helix model of glycine as a possible catalytic surface, present a divergence in the thermodynamic behavior (Figure 8(b)). From Figure 8(b), the dimerization of two L-alanine and two L,D alanine molecules are favored in the model of the L-helix glycine surface.

\section{Conclusion}

The obtained EPR results (Figure 1) confirm the presence of free radicals in glycine powder after irradiation with gamma radiation and before crystals assembly in water. Additionally, we show that the angles between the length of the crystals and the axis of the static magnetic field decrease at higher values of magnetic fields (Figure 2(c) and Figure 2(d)). In this first approach with static magnetic fields, we observed the formation of the two polymorphs of glycine crystals in the analysis of the FTIR and the second derivatives (variation of the band at 930 $\mathrm{cm}^{-1}$, Figure 4). In the cases with one magnet, the variation in this band is small, compared to the one at 10 magnets. By means of the polarized light microscopy, we detected long lasting fluid inclusions in the crystals of glycine (Figure 5 and Figure 6), nonetheless, the static magnetic field has no straightforward consequences on this process. In case of the impurities resulting from the irradiated glycine in the aqueous solution, we observe by MS certain unknown masses, which can be similar to glycine dimers and trimers of glycine united by the alpha 
carbon or possibly by hydrogen bonds (Figure 3 ). Other relevant conclusion is the presence of circular dichroism signal in the control $\gamma$ glycine crystals (Figure 7) contrasting with the lack of this signal in gamma irradiated glycine. The computer simulation studies suggest the formation of dimers, of glycine and chiral alanine, preferentially onto L-helix of glycine slabs confirming other studies [64] (Figure 10A and B). These considerations put forward the potential of glycine organic crystals in the ancient Earth to coordinate possibly with the magnetic fields, its catalytic activity to form higher molecular weight molecules in the dehydration processes. We focus on the possible computer simulations towards the formation of a variety of amino acid molecular machine. Our experimental and computer simulations show the necessity to perform further experimental and computer models to understand at the molecule-scale, the assembly or formation of glycine single crystals in different mineral surfaces. We are currently working to focus our studies on the interaction of static magnetic fields with chiral glycine single crystals and to figure out the different mechanisms that vanish the circular dichroism signal in irradiated samples. These studies are a breakthrough in chemical evolution, suggesting the capacity of glycine crystals to promote molecular complexity and supramolecular chemical heterogeneity. In other words, it is possible that ionizing radiation and magnetic fields contribute to the structural change of glycine single crystals, affecting the formation of the $\gamma$ polymorph with fluid inclusions on ancient Earth and in cometary conditions [10] [72] [73].

\section{Acknowledgements}

We thank M. in Educ. Isabel Mejía Luna (Departamento de Física, Facultad de Ciencias, UNAM), M.in Sc. V. Gómez Vidales (Instituto de Química, UNAM), (AH) to PAPIIT Project IN210119. We also thank M. in Sc. Audra Patterson for the edition of this manuscript and Tech. Acad. José Rangel Gutiérrez, Ing. Juan Eduardo Murrieta León, M. in Sc. Luciano Díaz González, BSc. Martín Cruz Villafañe, Luis Miguel Valdez Pérez, Mat. Enrique Palacios Boneta and Phys. Antonio Ramírez Fernández for all the technical assistance. We thank M. in Sci. Benjamín Leal and Phys. Francisco García for sample gamma irradiation.

\section{Conflicts of Interest}

The authors declare no conflicts of interest regarding the publication of this paper.

\section{References}

[1] Coyne, G.V. (1998) The Concept of Matter and Materialism in the Origin and Evolution of Life. In: Chela-Flores, J. and Raulin, F., Eds., Exobiology: Matter, Energy, and Information in the Origin and Evolution of Life in the Universe, Springer, Dordrecht, 71-80. https://doi.org/10.1007/978-94-011-5056-9 6

[2] Lemmon, R.M. (1973) Prebiotic Biochemistry (“Chemical Evolution”). Survey of Progress in Chemistry, 6, 47-82.

https://doi.org/10.1016/B978-0-12-610506-3.50008-X 
http://www.sciencedirect.com/science/article/pii/B978012610506350008X

[3] Fox, S.W. and Harada, K. (1960) The Thermal Copolymerization of Amino Acids Common to Protein. Journal of the American Chemical Society, 82, 3745-3751. https://doi.org/10.1021/ja01499a069

[4] Oro, J. (1983) Chemical Evolution and the Origin of Life. Advances in Space Research, 3, 77-94. https://doi.org/10.1016/0273-1177(83)90044-3

[5] Oró, J., Basile, B., Cortes, S., Shen, C. and Yamrom, T. (1984) The Prebiotic Synthesis and Catalytic Role of Imidazoles and Other Condensing Agents. Origins of Life, 14, 237-242. https://doi.org/10.1007/BF00933663

[6] Fox, S., Pleyer, H.L. and Strasdeit, H. (2019) An Automated Apparatus for the Simulation of Prebiotic Wet-Dry Cycles under Strictly Anaerobic Conditions. International Journal of Astrobiology, 18, 60-72. https://doi.org/10.1017/S1473550418000010

[7] Oró, J., Miller, S.L. and Lazcano, A. (1990) The Origin and Early Evolution of Life on Earth. Annual Review of Earth and Planetary Sciences, 18, 317-356. https://doi.org/10.1146/annurev.ea.18.050190.001533

[8] Nagayama, M., Takaoka, O., Inomata, K. and Yamagata, Y. (1990) Diketopiperazine-Mediated Peptide Formation in Aqueous Solution. Origins of Life and Evolution of Biospheres, 20, 249-257. https://doi.org/10.1007/BF01808107

[9] Ying, J., Lin, R., Xu, P., Wu, Y., Liu, Y. and Zhao, Y. (2018) Prebiotic Formation of Cyclic Dipeptides under Potentially Early Earth Conditions. Scientific Reports, 8, Article No. 936. https://doi.org/10.1038/s41598-018-19335-9

[10] Schreiber, U., Mayer, C., Schmitz, O.J., Rosendahl, P., Bronja, A., Greule, M., et al. (2017) Organic Compounds in Fluid Inclusions of Archean Quartz-Analogues of Prebiotic Chemistry on Early Earth. PLoS ONE, 12, e0177570.

https://doi.org/10.1371/journal.pone.0177570

[11] Betz, H. and Harvey, R.J. (2001) Glycine as a Neurotransmitter. In: John Wiley \& Sons Ltd., Ed., Encyclopedia of Life Sciences, John Wiley \& Sons Ltd., Chichester.

[12] Munegumi, T. (2014) Chemical Evolution of Simple Amino Acids to Asparagine under Discharge onto the Primitive Hydrosphere: Simulation Experiments Using Contact Glow Discharge. Bulletin of the Chemical Society of Japan, 87, 1208-1215. https://doi.org/10.1246/bcsj.20140164

[13] Guseva, E., Zuckermann, R.N. and Dill, K.A. (2017) Foldamer Hypothesis for the Growth and Sequence Differentiation of Prebiotic Polymers. Proceedings of the National Academy of Sciences, 114, E7460-E7468. https://doi.org/10.1073/pnas.1620179114

[14] Carny, O. and Gazit, E. (2005) A Model for the Role of Short Self-Assembled Peptides in the Very Early Stages of the Origin of Life. The FASEB Journal, 19, 10511055. https://doi.org/10.1096/fj.04-3256hyp

[15] Sugahara, H. and Mimura, K. (2014) Glycine Oligomerization Up to Triglycine by Shock Experiments Simulating Comet Impacts. Geochemical Journal, 48, 51-62. https://doi.org/10.2343/geochemj.2.0285

[16] Kamaluddin, K.A. (2012) Oligomerization of Glycine and Alanine on Metal(II) Octacynaomolybdate(IV): Role of Double Metal Cyanides in Prebiotic Chemistry. Amino Acids, 43, 2417-2429. https://doi.org/10.1007/s00726-012-1320-0

[17] Cole, J.P., Hanlon, A.M., Rodriguez, K.J. and Berda, E.B. (2017) Protein-Like Structure and Activity in Synthetic Polymers. Journal of Polymer Science Part A: Polymer Chemistry, 55, 191-206. https://doi.org/10.1002/pola.28378 
[18] Garrison, W.M. (1981) The Radiation Chemistry of Amino Acids, Peptides and Proteins in Relation to the Radiation Sterilization of High-Protein Foods. Radiation Effects, 54, 29-39. https://doi.org/10.1080/00337578108207124

[19] Sagstuen, E., Sanderud, A. and Hole, E.O. (2004) The Solid-State Radiation Chemistry of Simple Amino Acids, Revisited. Radiation Research, 162, 112-119. https://doi.org/10.1667/RR3215

[20] McLaughlin, J.P., Simopoulos, E.S. and Steinhäusler, F. (2005) The Natural Radiation Environment VII. Seventh International Symposium on the Natural Radiation Environment (NRE-VII), Rhodes, 20-24 May 2002.

[21] Ishikawa, K., Tanaka, M., Suzuki, T., Sekine, A., Kawasaki, T., Soai, K., et al. (2012) Absolute Chirality of the $\gamma$-Polymorph of Glycine: Correlation of the Absolute Structure with the Optical Rotation. Chemical Communications, 48, 6031. https://doi.org/10.1039/c2cc30549f

[22] Elsila, J.E., Glavin, D.P. and Dworkin, J.P. (2009) Cometary Glycine Detected in Samples Returned by Stardust. Meteoritics \& Planetary Science, 44, 1323-1330. https://doi.org/10.1111/j.1945-5100.2009.tb01224.x

[23] Biver, N., Bockelée-Morvan, D., Moreno, R., Crovisier, J., Colom, P., Lis, D.C., et al. (2015) Ethyl Alcohol and Sugar in Comet C/2014 Q2 (Lovejoy). Science Advances, 1, e1500863. https://doi.org/10.1126/sciadv.1500863

[24] Koga, T. and Naraoka, H. (2017) A New Family of Extraterrestrial Amino Acids in the Murchison Meteorite. Scientific Reports, 7, Article No. 636.

http://www.nature.com/articles/s41598-017-00693-9

https://doi.org/10.1038/s41598-017-00693-9

[25] Boldyreva, E.V., Drebushchak, V.A., Drebushchak, T.N., Paukov, I.E., Kovalevskaya, Y.A. and Shutova, E.S. (2003) Polymorphism of Glycine, Part I. Journal of Thermal Analysis and Calorimetry, 73, 409-418. https://doi.org/10.1023/A:1025405508035

[26] Boldyreva, E.V., Drebushchak, V.A., Drebushchak, T.N., Paukov, I.E., Kovalevskaya, Y.A. and Shutova, E.S. (2003) Polymorphism of Glycine, Part II. Journal of Thermal Analysis and Calorimetry, 73, 419. https://doi.org/10.1023/A:1025457524874

[27] Plankensteiner, K., Reiner, H. and Rode, B.M. (2005) Catalytic Effects of Glycine on Prebiotic Divaline and Diproline Formation. Peptides, 26, 1109-1112. https://doi.org/10.1016/j.peptides.2005.01.007

[28] Heredia, A., Colín-García, M., Puig, T.P., Alba-Aldave, L., Meléndez, A., CruzCastañeda, J.A., et al. (2017) Computer Simulation and Experimental Self-Assembly of Irradiated Glycine Amino Acid under Magnetic Fields: Its Possible Significance in Prebiotic Chemistry. Biosystems, 162, 66-74. https://doi.org/10.1016/j.biosystems.2017.08.008

[29] Suwannachot, Y. and Rode, B.M. (1998) Catalysis of Dialanine Formation by Glycine in the Salt-Induced Peptide Formation Reaction. Origins of Life and Evolution of Biospheres, 28, 79-90.

[30] Krishnamurthy, R. (2017) Giving Rise to Life: Transition from Prebiotic Chemistry to Protobiology. Accounts of Chemical Research, 50, 455-459. https://doi.org/10.1021/acs.accounts.6b00470

[31] Zolensky, M.E. (1999) Asteroidal Water within Fluid Inclusion-Bearing Halite in an H5 Chondrite, Monahans (1998). Science, 285, 1377-1379. https://doi.org/10.1126/science.285.5432.1377

[32] Sueda, M., Katsuki, A., Fujiwara, Y. and Tanimoto, Y. (2006) Influences of High 
Magnetic Field on Glycine Crystal Growth. Science and Technology of Advanced Materials, 7, 380-384. https://doi.org/10.1016/j.stam.2006.02.006

[33] Katsuki, A., Aibara, S. and Tanimoto, Y. (2006) Crystal Morphology Change by Magnetic Susceptibility Force. Science and Technology of Advanced Materials, 7, 385-388. https://doi.org/10.1016/j.stam.2006.02.005

[34] Iitaka, Y. (1960) The Crystal Structure of $\beta$-Glycine. Acta Crystallographica, 13, 35-45. https://doi.org/10.1107/S0365110X60000066

[35] Iitaka, Y. (1961) The Crystal Structure of $\gamma$-Glycine. Acta Crystallographica, 14, 1-10. https://doi.org/10.1107/S0365110X61000012

[36] Fleck, M. and Petrosyan, A.M. (2014) Salts of Amino Acids. Springer International Publishing, Cham. http://link.springer.com/10.1007/978-3-319-06299-0

[37] Bernal, J.D. (1931) The Crystal Structure of the Natural Amino Acids and Belated Compounds. Zeitschrift für Kristallographie-Crystalline Materials, 78, 363-369. https://doi.org/10.1524/zkri.1931.78.1.363

[38] Waldschmidt, A., Rietveld, I., Couvrat, N., Dupray, V., Sanselme, M., Berton, B., et al. (2011) About Aged Heterogeneous Liquid Inclusions inside Organic Crystals in Relation to Crystal Formation, Structure, and Morphology. Crystal Growth \& Design, 11, 2580-2587. https://doi.org/10.1021/cg200331n

[39] Osterrothová, K. and Jehlička, J. (2011) Investigation of Biomolecules Trapped in Fluid Inclusions inside Halite Crystals by Raman Spectroscopy. Spectrochimica Acta Part A: Molecular and Biomolecular Spectroscopy, 83, 288-296. https://doi.org/10.1016/j.saa.2011.08.032

[40] Goldman, N., Reed, E.J., Fried, L.E., William Kuo, I.-F. and Maiti, A. (2010) Synthesis of Glycine-Containing Complexes in Impacts of Comets on Early Earth. Nature Chemistry, 2, 949-954. https://doi.org/10.1038/nchem.827

[41] Rochette, P., Weiss, B.P. and Gattacceca, J. (2009) Magnetism of Extraterrestrial Materials. Elements, 5, 223-228. https://doi.org/10.2113/gselements.5.4.223

[42] Altwegg, K., Balsiger, H., Bar-Nun, A., Berthelier, J.-J., Bieler, A., Bochsler, P., et al. (2016) Prebiotic Chemicals-Amino Acid and Phosphorus-in the Coma of Comet 67P/Churyumov-Gerasimenko. Science Advances, 2, e1600285. https://doi.org/10.1126/sciadv.1600285

[43] Glavin, D.P., Aubrey, A.D., Callahan, M.P., Dworkin, J.P., Elsila, J.E., Parker, E.T., et al. (2010) Extraterrestrial Amino Acids in the Almahata Sitta Meteorite. Meteoritics \& Planetary Science, 45, 1695-1709. https://doi.org/10.1111/j.1945-5100.2010.01094.x

[44] Draganić, Z.D., Niketić, V. and Vujošević, S.I. (1985) Radiation Chemistry of an Aqueous Solution of Glycine: Compounds of Interest to Chemical Evolution Studies. Journal of Molecular Evolution, 22, 82-90. https://doi.org/10.1007/BF02105808

[45] López-Esquivel Kranksith, L., Negrón-Mendoza, A., Mosqueira, F.G. and Ramos-Bernal, S. (2010) Radiation-Induced Reactions of Amino Acids Adsorbed on Solid Surfaces. Nuclear Instruments and Methods in Physics Research Section A: Accelerators, Spectrometers, Detectors and Associated Equipment, 619, 51-54. https://doi.org/10.1016/j.nima.2009.11.080

[46] Silva, P., Albano, C. and Perera, R. (2008) Use of Electron Paramagnetic Resonance to Evaluate the Behavior of Free Radicals in Irradiated Polyolefins. Revista Latinoamericana de Metalurgia y Materiales, 28, 79-90.

[47] Thomas, P.J., Hicks, R.D., Chyba, C.F. and McKay, C.P. (2006) Comets and the Origin and Evolution of Life. Advances in Astrobiology and Biogeophysics, 2nd 
Edition, Springer-Verlag, Berlin. https://doi.org/10.1007/3-540-33088-7 https://www.springer.com/gp/book/9783540330868

[48] Guillory, J.K. (2003) Handbook of Aqueous Solubility Data by Samuel H. Yalkowsky and Yan He. CRC Press, Boca Raton, FL. xii +1496 pp. $18 \times 26 \mathrm{~cm}$. ISBN 0-89493-1532-8. \$299.95. Journal of Medicinal Chemistry, 46, 4213. https://doi.org/10.1021/jm0303251

[49] Pilling, S., Mendes, L.A.V., Bordalo, V., Guaman, C.F.M., Ponciano, C.R. and da Silveira, E.F. (2013) The Influence of Crystallinity Degree on the Glycine Decomposition Induced by $1 \mathrm{MeV}$ Proton Bombardment in Space Analog Conditions. Astrobiology, 13, 79-91. https://doi.org/10.1089/ast.2012.0877

[50] de la Cruz-López, A., del Ángel-Meraz, E., Colín-García, M., Ramos-Bernal, S., Negrón-Mendoza, A. and Heredia, A. (2016) Ultraviolet Irradiation of Glycine in Presence of Pyrite as a Model of Chemical Evolution: An Experimental and Molecular Modelling Approach. International Journal of Astrobiology, 16, 237-243.

[51] de Aragão, B.J.G. and Messaddeq, Y. (2008) Peak Separation by Derivative Spectroscopy Applied to FTIR Analysis of Hydrolized Silica. Journal of the Brazilian Chemical Society, 19, 1582-1594.

https://doi.org/10.1590/S0103-50532008000800019

[52] Rieppo, L., Saarakkala, S., Närhi, T., Helminen, H.J., Jurvelin, J.S. and Rieppo, J. (2012) Application of Second Derivative Spectroscopy for Increasing Molecular Specificity of Fourier Transform Infrared Spectroscopic Imaging of Articular Cartilage. Osteoarthritis and Cartilage, 20, 451-459. https://doi.org/10.1016/j.joca.2012.01.010

[53] Gunter, M.E. (2004) The Polarized Light Microscope: Should We Teach the Use of a 19th Century Instrument in the 21st Century? Journal of Geoscience Education, 52, 34-44. https://doi.org/10.5408/1089-9995-52.1.34

[54] Phelps, P. (1968) Compensated Polarized Light Microscopy: Identification of Crystals in Synovial Fluids from Gout and Pseudogout. JAMA, 203, 508. https://doi.org/10.1001/jama.1968.03140070064014

[55] Kerr, P.F. (1972) Mineralogía óptica. Ediciones del Castillo. 433 p.

[56] Raith, M.M., Raase, P. and Reinhardt, J. (2011) Leitfaden zur Dünnschliffmikroskopie. http://www.dmg-home.de/pdf/Leitfaden zur Duennschliffmikroskopie-2011.pdf

[57] Klein, E., Matis, M., Lukeš, V. and Cibulková, Z. (2006) The Applicability of AM1 and PM3 Semi-Empirical Methods for the Study of N-H Bond Dissociation Enthalpies and Ionisation Potentials of Amine Type Antioxidants. Polymer Degradation and Stability, 91, 262-270. https://doi.org/10.1016/j.polymdegradstab.2005.05.010

[58] Collins, M.A. and Grant, R.A. (1969) Ultraviolet Light Induced Free Radicals in Glycine Peptides in the Solid State. Photochemistry and Photobiology, 9, 369-375. https://doi.org/10.1111/j.1751-1097.1969.tb07301.x

[59] Talbi, S., Raffi, J., Aréna, S., Colombani, J., Piccerelle, P., Prinderre, P., et al. (2004) EPR Study of Gamma Induced Radicals in Amino Acid Powders. Spectrochimica Acta Part A: Molecular and Biomolecular Spectroscopy, 60, 1335-1341. https://doi.org/10.1016/j.saa.2003.10.031

[60] Osmanoğlu, Y.E., Sütçü, K. and Osmanoğlu, Ş. (2017) Radiation Effect Studies on Some Glycine Derivatives in Solid State. Radiation Effects and Defects in Solids, 172, 621-628. https://doi.org/10.1080/10420150.2017.1371171

[61] De Bie, M.J.A. and Braams, R. (1969) Crystal Lattice Dependency of the Free Radicals Found in Irradiated Glycine. Chemical Physics Letters, 4, 331-332. 
https://doi.org/10.1016/0009-2614(69)80253-8

[62] Gilbert, B.C., Davies, M.J. and McLauchlan, K.A. (2000) Electron Paramagnetic Resonance. Electron Paramagnetic Resonance Vol. 17, Royal Society of Chemistry, Cambridge. https://doi.org/10.1039/9781847553546

[63] Ogawa, K., Yagi, F., Suzuki, E., Guzman, L.A. and Shimizu, K. (2002) Magnetic Orientation of Amino Acid Crystals. Journal of Chemical Engineering of Japan, 35, 1123-1132. https://doi.org/10.1252/jcej.35.1123

[64] Rodriguez-Garcia, M., Surman, A.J., Cooper, G.J.T., Suárez-Marina, I., Hosni, Z., Lee, M.P., et al. (2015) Formation of Oligopeptides in High Yield under Simple Programmable Conditions. Nature Communications, 6, 8385.

https://doi.org/10.1038/ncomms9385

[65] Rosado, M.T., Duarte, M.L.T.S. and Fausto, R. (1998) Vibrational Spectra of Acid and Alkaline Glycine Salts. Vibrational Spectroscopy, 16, 35-54. https://doi.org/10.1016/S0924-2031(97)00050-7

[66] Srinivasan, K. (2008) Crystal Growth of $\alpha$ and $\gamma$ Glycine Polymorphs and Their Polymorphic Phase Transformations. Journal of Crystal Growth, 311, 156-162. https://doi.org/10.1016/j.jcrysgro.2008.10.084

[67] Balakrishnan, T., Babu, R.R. and Ramamurthi, K. (2008) Growth, Structural, Optical and Thermal Properties of $\gamma$-Glycine Crystal. Spectrochimica Acta Part A: Molecular and Biomolecular Spectroscopy, 69, 1114-1118.

https://doi.org/10.1016/j.saa.2007.06.025

[68] Valev, V.K., Smisdom, N., Silhanek, A.V., De Clercq, B., Gillijns, W., Ameloot, M., et al. (2009) Plasmonic Ratchet Wheels: Switching Circular Dichroism by Arranging Chiral Nanostructures. Nano Letters, 9, 3945-3948. https://doi.org/10.1021/nl9021623

[69] Bujdak, J., Slosiarikova, H., Texler, N., Schwendinger, M. and Rode, B.M. (1994) On the Possible Role of Montmorillonites in Prebiotic Peptide Formation. Monatshefte für Chemiel Chemical Monthly, 125, 1033-1039.

https://doi.org/10.1007/BF00811510

[70] Bujdák, J. and Rode, B.M. (1997) Glycine Oligomerization on Silica and Alumina. Reaction Kinetics and Catalysis Letters, 62, 281-286. https://doi.org/10.1007/BF02475464

[71] Paradowska, J., Stodulski, M. and Mlynarski, J. (2009) Catalysts Based on Amino Acids for Asymmetric Reactions in Water. Angewandte Chemie International Edition, 48, 4288-4297. https://doi.org/10.1002/anie.200802038

[72] Bobo, E., Lefez, B., Caumon, M.-C., Petit, S. and Coquerel, G. (2016) Evidence of Two Types of Fluid Inclusions in Single Crystals. CrystEngComm, 18, 5287-5295. https://doi.org/10.1039/C6CE00956E

[73] Eschenmoser, A. (2007) The Search for the Chemistry of Life's Origin. Tetrahedron, 63, 12821-12844. https://doi.org/10.1016/j.tet.2007.10.012 